Acta Poetica 28 (1-2)

PRIMAVERA-OTOÑO

2007

\title{
Estéticas del residuo en el Chile del postgolpe. Walter Benjamin y la escena de avanzada
}

\author{
Macarena Ortúzar Vergara
}

El siguiente trabajo pretende explicar el abrupto cambio estético que se produjo en Chile a comienzos de la dictadura con la llamada "escena de avanzada", a partir de la noción de "pobreza de la experiencia" que propone Walter Benjamin (1933). Ante una experiencia incomunicable, la nueva escena recurre a un lenguaje fragmentado, que se detiene en aquellos residuos de una historia cuyo transcurrir había sido, también, fragmentado. Más que transformar una experiencia escindida en una totalidad, la escena de avanzada pretendió hablar de ella generando nuevos lenguajes que, a la manera del cronista benjaminiano, pusieran el acento en los residuos de la experiencia y en todo aquello que había sido expulsado del continuum de la historia.

The following study suggests that the concept "poverty of experience" proposed by Walter Benjamin (1933) explains the abrupt aesthetic change that took place in Chile, at the beginning of the dictatorship, with the so called escena de avanzada. Facing an incommunicably experience, the nueva escena resorts to fragment the language, and stops in the remains of a history, whose transition had been also fragmented. Rather than transforming a fractured experience in a totality, the escena de avanzada pretended to talk about herself by generating new languages that put emphasis on the experience remains and in all that had been expelled of the continuum of the history, as Benjamin's chronicler does. 

Acta Poetica 28 (1-2)

PRIMAVERA-OTOÑO

2007

Macarena Ortúzar Vergara

FFyL, UNAM

Estéticas del residuo en el Chile del postgolpe.

Walter Benjamin y la escena de avanzada

las banderas de Chile ondearon como un harapo sobre los colores que miraban hasta que desgarrados no hubo colores en sus banderas sino apenas un jirón cubriéndoles los cuerpos aún vivos entumidos decolorándose en la playa

RAÚl ZuRITA, "Las playas IX”

En "Experiencia y pobreza" (1933), Benjamin dice que las personas que volvían de la guerra "regresaban mudas del campo de batalla. No enriquecidas, sino más pobres en lo referente a experiencias comunicables" (Benjamin 1982, 134). Un punto especialmente interesante de esta breve cita se encuentra en la idea de "experiencia comunicable". ${ }^{1}$ Se trata de una pobreza de experiencia como experiencia contada, como memoria. En palabras de Sarlo, para Benjamin "no hay narración sin

\footnotetext{
${ }^{1}$ Nos referimos a la Erfahrung en el sentido de experiencia para ser contada. Cf. Los narradores de Auschwitz de Esther Cohen, 2006, pp. 65-66.
} 
experiencia, pero tampoco hay experiencia sin narración: el lenguaje libera lo mudo de la experiencia, la redime de su inmediatez y la convierte en lo comunicable, es decir lo común" (Sarlo 2004, 33-34).

Desde este punto de vista, experiencia y relato son inseparables. Pero, si son inseparables, ¿cómo vive el horror aquel que no tuvo palabras para nombrarlo? La pobreza de la experiencia es el enmudecimiento rotundo del cuerpo que resistió la tortura con un "corte de pensamiento" (testimonio en Grau 2004, 78). La experiencia de la muerte, la violación, las vejaciones, el hambre, la humillación sólo parecen posibles empobreciendo la experiencia: interrumpir el pensamiento, interrumpir la memoria, interrumpir para sobrevivir. Superar esta fractura transmitiendo la experiencia sería la única forma de superar el shock de lo vivido. Se trata de "la redención del pasado por la memoria" (Sarlo 2004, 36).

Muchas personas, desde la dictadura chilena (1973-1990), intentaron hacer suya la experiencia a través de la palabra. Hablaron, aunque fuese a duras penas, para restablecer una continuidad que se veía violentamente fracturada. Continuidad de experiencia, lenguaje y memoria; continuidad histórica y continuidad del lazo social. Pero, ¿cuál es el lenguaje que se levanta apenas, desde la pobreza, desde la fractura de la memoria, e intenta comunicar, hacer propio, lo alienado?

Los escritores de todas las tendencias poéticas que convergieron en el postgolpe debieron enfrentar varios cambios sustantivos al panorama poético. Primero, una breve pero profunda discontinuidad a raíz del desmantelamiento o intervención de universidades, talleres, editoriales, revistas; además de la desaparición y dispersión, mayoritariamente por la clandestinidad, el presidio, la desaparición o el exilio de buena parte de los personajes que conformaban dicho panorama. En segundo lugar, los poetas que permanecieron en el país vieron su poesía marcada por las particulares condiciones de la vida cotidiana, 
pero sobre todo por la precariedad de la producción y circulación de textos. ${ }^{2}$

Todos ellos intentaron una memoria, guardaron memoria, transmitieron la memoria porque era la única forma de hacer propia la experiencia e inscribirla en el tejido de la tradición y de la comunidad. ${ }^{3}$ Intentaron fijar, insistentemente, a la manera del cronista benjaminiano, lo grande y lo pequeño para que "nada de lo que alguna vez aconteció pueda darse por perdido para la historia” (Benjamin 1995, 49).

Relegar el horror a un punto de la historia, impedirle la circulación, fracturar la memoria y la experiencia, es una forma de negarlo y negar con ello a las víctimas: "Por ello la escritura se convierte en una lucha contra el olvido, en una facultad política, en un momento ético donde el otro, el "hundido", cobra vida a través de la pluma del escritor y del sobreviviente" (Cohen 2006, 17).

Desde el punto de vista de Nelly Richard han sido tres los principales factores que han llevado en Chile a la memoria desmembrada y cuya imagen más patente es la de los cuerpos aún sin sepultar, los $\mathrm{NN}$ que esperan una narración de su muerte:

Primero, la amenaza de su pérdida [de la memoria] cuando la toma de poder de 1973 seccionó y mutiló el pasado anterior al corte fundacional del régimen militar. Segundo, la tarea de su

\footnotetext{
${ }^{2}$ A pesar de lo anterior, resulta sorprendente constatar la enorme producción de poesía en autoediciones, papeles mecanografiados, fotocopias o casettes en el postgolpe chileno. Se produjo, después de 1973 - al interior del país y en el exilio-, una cantidad mucho mayor de poesía que la que se generaba antes del golpe. Según Thomas Harris, en 1974 se publicaron 120 libros de poesía, en tanto que en 1985 se publicaron 140, cifras de producción que sobrepasan con creces a las de antes del golpe. Cf. "Desarrollo de la poesía chilena: 1960 (1973) 1990" de Thomas Harris en Mapocho. Revista de humanidades, 51 (primer semestre de 2002).

3 Tendencias poéticas que convergieron durante la dictadura, desde las testimoniales hasta las más experimentales, aun con sus grandes diferencias y con la disgregación, están marcadas por la pregunta sobre la realidad.
} 
recuperación cuando el país fue recobrando vínculos de pertenencia social a su tradición democrática. Y tercero, el desafío de su pacificación cuando una comunidad dividida por el trauma de la violencia homicida busca reunificarse en el escenario postdictatorial, suturando los bordes de la herida que separa el castigar del perdonar (Richard 1994, 13).

El nombre de "transición" con que se llamó en Chile a los primeros años de retorno a la democracia (a partir de 1990) expresaba, precisamente, un deseo de restablecimiento de la continuidad, esto es, recuperación. Deseo y necesidad de hacer un trabajo de memoración - que no se ha cumplidoque generara una narración, una continuidad entre los hechos que fracturaban el cuerpo nacional. La memoria desmembrada a la que se refiere Nelly Richard persiste, la transición no ha marcado el ansiado tránsito que recogería las ruinas que sobrevivieron a la catástrofe del sentido. La transición - si es posible - o la narración de esa historia de fracturas y residuos pasaría, no por obviar dichas fracturas, sino por recorrer "sus puntas y escarpaduras, que obligan a detenerse a quien quiere pasar por sobre ellas" (Benjamin 1995, 92).

Es la amenaza de pérdida de la memoria y la falta de un lenguaje que diera cuenta de ella la que se deja traslucir en las obras de la neovanguardia chilena. ${ }^{4}$ Será una recuperación fragmentaria y carente del habla y de la memoria, en un contexto en el que comunicar era un acto de peligrosidad por sí mismo y en el que no había un lenguaje total capaz de decir lo que era necesario transmitir.

La pobreza de la experiencia consiste, entonces, en un problema de los límites del lenguaje, de los límites del sujeto y

\footnotetext{
${ }^{4}$ La crítica chilena dio el nombre de "neovanguardia", "nueva escena" o "escena de avanzada" al campo no oficial de la producción artística gestada bajo la dictadura, que se caracterizó por una fuerte ruptura con la tradición estética anterior y la corrosión, en general, de los grandes postulados en torno al arte, los géneros, los soportes y el sujeto.
} 
también de los límites de lo que era posible imaginar como experiencia. Una vez que el horror de la dictadura pasó a través de los cuerpos de miles de chilenos, el lenguaje no podía quedar intacto.

Es desde allí desde donde habla Raúl Zurita en el prólogo a La experiencia autoritaria (1981) de José Joaquín Brunner:

No es que la victoria —o la derrota- sea absoluta, es más bien el intento por hacerla aparecer como absoluta lo que marca, en definitiva, el quiebre con el pasado. Ello no es solamente un asunto de palabras, pero también pasa por las palabras: no se borra un país (eso sería solamente una idea), lo que se borra es la consistencia de su lenguaje [...] (Zurita 1981, 7).

El quiebre con el pasado es, para el poeta, una pérdida de consistencia en el lenguaje que permitiría la narración, el restablecimiento de la continuidad. Así, hay quienes durante la dictadura intentaron una escritura, a través de este lenguaje sin consistencia, desde la precariedad más absoluta, generando nuevos códigos para decir esa fractura: un "alfabeto de las huellas a reciclar mediante precarias economías del trozo y la traza" (Richard 1994, 14).

La ruptura, encarnada para la tradición del arte chileno por la escena de avanzada, nacía precisamente del intento de adopción de nuevas formas que permitieran la enunciación de fragmentos de experiencia que tanto el lenguaje anterior al Golpe como aquél "sin consistencia" que se fundó tras él no podían expresar.

[...] el lenguaje de la antipoesía fue incapaz de dar cuenta de ese quiebre, digamos, perceptivo a partir de 1973. ¿Por qué? Porque era de un optimismo increíble: creía efectivamente que el lenguaje oral, el lenguaje de las conversaciones, tenía una salida mejor que las otras... Pero después del 73 , ¿te fijas?, nos preguntamos qué fue de tanta conversación, ¿no? (Zurita en O’ Hara 1996, 106). 
En este comentario de Zurita se expresa con toda claridad la certeza de los artistas del postgolpe de que el lenguaje había cambiado para siempre. La violencia inflingida sobre la percepción, la comunicación y la historia había sido demasiado profunda. El lenguaje de la antipoesía se volvió así, abruptamente, un lenguaje de otra época. Lo mismo hace notar Adriana Valdés respecto de Enrique Lihn y Neruda:

En los años ochenta y al contrario del famoso "yo vengo a hablar por vuestra "boca muerta" del vate, [Lihn] dice "en una lengua muda tendría que cantar y que no generalizara [...] en una lengua de plástico intrínsecamente amordazada y por supuesto desechable...". Tal vez "Made in Taiwan" como las baratijas del Paseo Ahumada de entonces. Porque, dirá en 1987, "como ciudadanos de un mundo fascistoide estamos contaminados de lo que repudiamos (en Valdés 2004, 163).

Neruda ya no era posible después de 1973. La escena de avanzada y otros artistas de la época estaban convencidos de que ésa no era otra cosa que el reverso del lenguaje dictatorial. Había que cambiar los lenguajes, hacer saltar los soportes y los géneros y hablar la lengua de la carencia.

Volvemos, entonces, a la pregunta inicial: ¿Cómo es posible narrar el horror, si en él hay un "corte de pensamiento", un empobrecimiento de la experiencia comunicable? Creemos que, en las formulaciones más novedosas del arte del postgolpe, la respuesta se dio sobre un no rotundo al lenguaje totalizante y de lo total. Memoria y experiencia se divorciarían de las visiones globales, plenamente articuladas de la memoria. Se trata de una concepción de la memoria que hace estallar las ideas de sucesión cronológica y globalidad:

El pasado es un campo de citas atravesado tanto por la continuidad (las formas de suponer o imponer una idea de sucesión) como por las discontinuidades: por los cortes que interrumpen 
la dependencia de esa sucesión a una cronología predeterminada. Sólo hace falta que ciertos trances críticos desaten esa reformulación heterodoxa para que las memorias trabadas por la historia desaten sus nudos de temporalidades en discordias (Richard 2000, 14).

Juan Luis Martínez tematiza en uno de sus poemas más conmovedores esta pérdida del código, de las señales. Un padre de familia ve desaparecer a cada uno de sus seres queridos al interior de la casa (patria) para terminar, justo antes de desaparecer él mismo, diciendo:

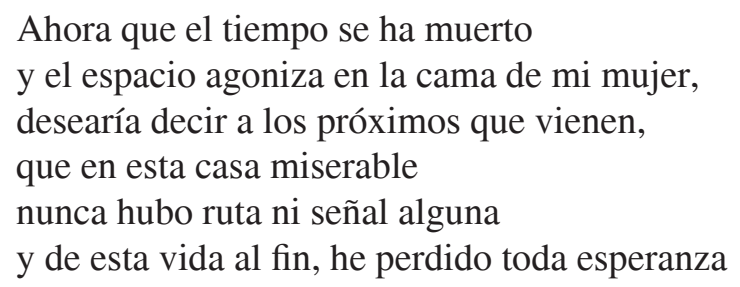

(Martínez 1985, 137)

Al comienzo del poema, el padre advierte a los miembros de su familia sobre el peligro de desatender las señales, sobre la posibilidad de que éstas se borren; pero una vez que la familia ha desaparecido le es revelado al padre que "nunca hubo ruta ni señal alguna".

Este lenguaje de la pobreza no fue otro que el lenguaje del residuo y de la pérdida de señales. Ante la imposibilidad de un lenguaje que unificara la experiencia, la neovanguardia se centra en los residuos que la historia oficial iba dejando en los márgenes. Así lo expresa con toda claridad Diamela Eltit en la presentación de El Padre Mio (1989), ${ }^{5}$ texto para el cual la au-

\footnotetext{
${ }^{5}$ El texto se basa en el Padre Mío, nombre que da Eltit a un vagabundo cuyos monólogos graba y transcribe la autora. Así, el libro consta de tres partes, que corresponden a tres "hablas" del Padre Mío grabadas en 1983, 1984 y 1985. El texto se puede encontrar en <http://www.memoriachilena.cl>.
} 
tora dedicó años de exploración en los márgenes de la ciudad, centrándose en los vagabundos cuya

exterioridad se construía desde la acumulación del desecho y la disposición para articular una corporalidad barroca temible en su exceso. [...] Cargando todas sus pertenencias en bolsas, sacos o paquetes, esos bultos eran una apariencia más. El símil de la propiedad individual y, más aún, la copia de una historia personal marcada por la posesión de objetos testimoniadores de la existencia de un pasado. De esta manera, la elaboración de significaciones sólo era legible en la suma de síntomas externos que se ponían a operar (Eltit 1989, 12).

El simulacro de historia personal, del testimonio de un pasado a través del bulto, de los desechos de la sociedad, es el lenguaje que adoptaron los jóvenes artistas de la nueva escena en un barroco igualmente temible al de El Padre Mío. Un negativo que, viniendo del margen, hablaba con su existencia del positivo ubicado al centro: "En algún lugar era posible suponer que en sus cuerpos estaban impresos los grafismos de todos los otros -lo institucional_-" (Eltit 1989, 13). La pobreza de la experiencia devino, durante el posgolpe chileno, en un lenguaje del vagabundeo, precisamente porque esa era la única manera de expresar a Chile con los residuos de su pasado y la fractura presente:

[El Padre Mío] Es Chile, pensé. Chile entero y a pedazos en la enfermedad de este hombre; jirones de diarios, fragmentos de exterminio, sílabas de muerte, pausas de mentira, frases comerciales, nombres de difuntos. Es una honda crisis del lenguaje, una infección en la memoria, una desarticulación en todas las ideologías. Es una pena, pensé (Eltit 1989, 17).

La forma de hablar desde la desarticulación del postgolpe era, desde el punto de vista de la escena de avanzada, precisa- 
mente, desde esa infección de la memoria. Un habla supurante, pero imperiosa, que insistía en el fragmento y el margen, como había propuesto Benjamin desde otra crisis.

Activar la memoria a fragmentos, pero sacarla del enmudecimiento, fue la consigna de las acciones de arte del grupo CADA. ${ }^{6}$ El artista para el CADA era un "obrero de la experiencia" y el arte sólo tenía sentido como "experiencia corregida". Por ejemplo, en la primera acción de arte (1979) se leyó un texto frente a la CEPAL que decía: "[...] ir creando las verdaderas condiciones de vida de un país no es sólo un trabajo político [...] corregir la vida es un trabajo de arte" (en Neustadt 2001, 128). De hecho, éstos son los fundamentos de todas las acciones de arte que realizó el colectivo y de buena parte de la producción individual de sus integrantes tras la disolución del grupo. ${ }^{7}$

Raúl Zurita reafirma en una entrevista, aunque refiriéndose a su propia producción poética: "entender la construcción de un cuerpo social como única obra de arte valedera [...] asumir la propia vida y la de todos como el único producto de arte que merece ser sociabilizado. O sea la vida entendida como obra por construir" (en O'Hara 1996, 104).

El problema de la fractura de la totalidad en los procesos sociales no era independiente del problema del sistema de producción y circulación de arte. Desarticular los compartimentos estancos de política, arte, y vida, haciendo difusos los límites por medio de las acciones de arte y del artista como obrero

\footnotetext{
${ }^{6}$ Colectivo de Acciones de Arte, conformado por Zurita, Eltit, Rosenfeld, Dittborn y Balcells que se inscribe en el marco de la nueva escena o escena de avanzada. Para un análisis de los postulados y el lugar que ocupó el CADA en la escena de avanzada, puede verse "Una cita limítrofe entre neovanguardia y postvanguardia" en La insubordinación de los signos de Nelly Richard y CADA DÍA, la creación de un arte social de Robert Neustadt.

${ }^{7}$ Las acciones de arte pretendían corregir la vida entendiéndola como obra de arte y no cambiar la política o la vida a través del arte, entendido como una esfera distante de "lo social".
} 
de la experiencia, no era, por tanto, solamente una crítica a la institución del museo, sino que además intentaba reestablecer una experiencia fracturada en términos del cuerpo, el lenguaje y sus relaciones con el mundo.

En “Ay! Sudamérica”, la segunda acción de arte del grupo, se dejaron caer 400.000 volantes sobre Santiago desde aviones de la Fuerza Aérea:

Estábamos entre el 79 y el 80, en dictadura, a un plazo muy cercano del golpe de estado. Entonces nosotros teníamos muy presente el bombardeo de la Moneda. Nosotros quisimos citar, activar la memoria de ese bombardeo con estas avionetas: citar y revertir a la vez el bombardeo del golpe. Es una metáfora débil, pero era lo que nosotros podíamos hacer en ese momento (Eltit 2004, 45).

Es particularmente interesante que el CADA haya acuñado el término de "experiencia corregida" 8 y que éste fuese un eje central de su propuesta. Frente a la pobreza de la experiencia, el CADA se levanta bajo el signo de la experiencia corregida; aunque fuese con una "metáfora débil".

Otra de las acciones de arte fue "Viuda" que consistió en la inserción de una fotografía en diversas revistas bajo la consigna: "Mirar su gesto extremo y popular. / Prestar atención a su viudez y sobrevivencia. / Entender a un pueblo. VIUDA".

\footnotetext{
${ }^{8}$ Experiencia individual, biográfica, pero antes que nada, experiencia colectiva. Así lo muestran las acciones de arte, entre las cuales está "Ay! Sudamérica" y "Para no morir de hambre en el arte". En "Para no morir de hambre..." se llevaron a cabo seis acciones programadas simultáneamente, anotamos algunas: los artistas distribuyen cien litros de leche entre familias de un sector pobre de Santiago; se publica en la revista Hoy, desviando su función periodística, el siguiente texto: "Imaginar esta página completamente blanca / imaginar esta página blanca como la leche diaria a consumir / imaginar cada rincón de Chile privado del consumo diario de leche como páginas blancas para llenar". Diez camiones lecheros desfilan por la ciudad desde un centro productor de leche hacia un museo; se lee frente a la sede de la ONU un texto en cinco idiomas que retrata a Chile en su precariedad y marginación.
} 
Texto firmado por Mujeres por la vida y CADA, fechado en septiembre de $1985 .{ }^{9}$

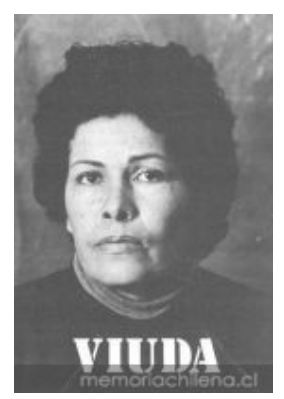

El cuerpo se vuelve fundamental en el lenguaje de la nueva escena chilena, porque afirma una existencia. ${ }^{10}$ Obliga a la circulación de aquellos sujetos sociales que han sido expulsados de la historia oficial. Es la falta de circulación la que impide la experiencia. Así, la nueva escena se empeñará en que los jirones de la experiencia circulen y salgan del mutismo: "Mirar", "Prestar atención", "Entender" un gesto extremo que marca la existencia de aquellos sujetos que habían sido borrados del discurso hegemónico. Pero un cuerpo ajado se expresa también en un lenguaje ajado: "La narración está unida al cuerpo y a la voz" (Sarlo 2004, 33).

El CADA puso el acento sobre la experiencia haciendo transitar por la esfera pública sujetos o acontecimientos que

\footnotetext{
${ }^{9}$ Una copia de esta inserción puede verse en el libro de Neustadt (referencia en la bibliografía final).

${ }^{10}$ El cuerpo no sólo aparecerá mencionado muy a menudo en las obras de la neovanguardia, sino que también será materia de arte y soporte de arte. Las violencias infligidas por la dictadura sobre los cuerpos a través del presidio, la tortura, la restricción de movimiento, el exilio, el toque de queda, etc. son subvertidas al asumir el cuerpo como soporte de significaciones, de arte, de sentido que se mantiene como un reducto de libertad en pugna, como lo más íntimo que se ve intervenido, pero que también se está defendiendo a sí mismo en el hecho de aparecer y, por tanto, significar. De ahí lo desafiante del gesto.
} 
habían sido arrancados del discurso de lo nacional, en palabras de Benjamin, haciéndoles justicia del único modo posible: "Yo no tengo nada que decir. Sólo que mostrar. No voy a hurtar nada valioso ni me apropiaré de formulaciones ingeniosas. Pero los andrajos, los deshechos: ésos no los voy a inventariar, sino hacerles justicia del único modo posible: usándolos" (Benjamin 1995, 125).

La primera edición de Purgatorio abre con la fotografía del rostro quemado del autor en la portada. ${ }^{11}$ Leemos esta imagen, entre otras cosas, como una manifestación de la concepción de arte que unía la producción estética a la vida, el cuerpo y el cuerpo social. Posteriormente, aparece el epígrafe que abre el poemario: "Mis amigos creen que / estoy muy mala / porque quemé mi mejilla". Ya desde esa apertura estamos en presencia de una de las grandes indeterminaciones a las que se somete la voz de Purgatorio: femenino/masculino. Oscilación que rompe una de las más importante categorías binarias del lenguaje. ${ }^{12}$ Esta indeterminación se verá profundizada en las primeras páginas del libro, donde se ve al autor vendado y se lee en la página siguiente, con letra manuscrita:

Me llamo Raquel

estoy en el oficio hace varios

años. Me encuentro

en la mitad de

mi vida. Perdí

el camino.

\footnotetext{
${ }^{11}$ Las fotografías reproducidas corresponden a la primera edición del libro; en las citas trabajaremos con la edición de 1996, que corresponde a la cuarta edición. En caso de que se presenten diferencias entre la primera edición y la cuarta, lo consignaremos a pie de página.

${ }^{12}$ La forma en que la literatura habrá de subvertir el discurso de la univocidad y la impermeabilidad consiste principalmente en la creación de discursos plurales y fragmentarios, que abren sus sentidos a través de la polisemia o la ambigüedad, generando una constante fluctuación que tiende a borrar, movilizar, permeabilizar los límites identitarios y las categorías excluyentes.
} 


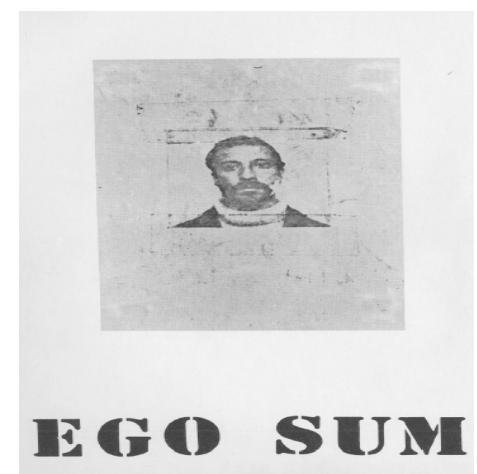

Dado que un autor masculino ingresa en la obra con su biografía, a través de la fotografía - la mejilla quemada con una venda-, el texto manuscrito "Me llamo Raquel..." constituye una clara ruptura de la expectativa del lector. ${ }^{13} \mathrm{El}$ ingreso de la voz femenina, de la locura y, en general, de todos los personajes borrados del discurso identitario nacional es característica del arte de la escena de avanzada. Así, Maquieira abre La Tirana con una voz femenina que intenta recordar desde la afirmación más radical "Yo":

Yo, La Tirana, rica y famosa
la Greta Garbo del cine chileno
pero muy culta y calentona, que comienzo
a decaer, que se me va la cabeza
cada vez que me pongo a hablar
y hacer recuerdos de mis polvos con Velázquez

(Maquieira 25)

En definitiva, la propuesta de la escena de avanzada en Chile fue la de "cepillar la historia a contrapelo" (Benjamin 1995,

${ }^{13}$ En términos de la inclusión de la propia vida este manuscrito funcionaría de la misma manera que el de Roland Barthes, en Barthes por Barthes: "Tout ceci doit être considéré comme dit par un personnage de roman" (10). Expresa, por una parte, el enmascaramiento, pero también afirma la certeza de una existencia (lo corporal) a través de la escritura personal, manuscrita. 
91) por medio de la creación de un lenguaje a contrapelo. Estos escritores del postgolpe en Chile se enfrentaron a la necesidad de hacer circular la experiencia fragmentada y silenciada, estructurando una nueva estética que fuese capaz de decir la carencia y la fractura de la experiencia. Aún con la oblicuidad, la oscilación y el enmascaramiento sobre los cuales se despliegan estas propuestas; no hay en ellas el enmudecimiento que hubiese constituido una fractura aún mayor en la memoria chilena.

El lenguaje de la carencia que adoptó la escena de avanzada se destaca por poner el acento en lo residual y marginado. La acumulación de fragmentos, como los bultos del Padre Mío, intentan reproducir - hasta el delirio - la construcción de una memoria, afirmando una experiencia. Guardarlo todo y adherirlo todo para que nada sea borrado. La corrección de la experiencia, como la llamó el CADA, consistía más bien en la constitución de una experiencia, imprimiéndola en la memoria. Y esa memoria, tras el bombardeo de La Moneda, se expresaría en el lenguaje de la ruina.

La dictadura chilena constituyó un derrumbe del sentido a tal punto que ni siquiera la sensibilidad del testimonio fue posible para los jóvenes artistas de la neovanguardia. ¿Cómo fue el testimonio del arte? Fue un testimonio del desecho, la errata y la ruina que retomó todos los restos de la historia mientras deambulaba por los márgenes de la ciudad y dormía en las fachadas de los edificios como El Padre Mío de Diamela Eltit.

\section{BIBLIOGRAFÍA}

Benjamin, Walter, La dialéctica en suspenso. Fragmentos sobre la historia, trad. Pablo Oyarzún, Santiago de Chile, LOM/ARCIS, 1995. 
Benjamin, Walter, "Experiencia y pobreza", en Para una crítica de la violencia, México, Nave de los locos, 1982.

CoHen, Esther, Los narradores de Auschwitz, México, Buenos Aires, Fineo-Lilmond, 2006.

Eltit, Diamela, El Padre Mío, Santiago, Francisco Zegers Editor, 1989.

— "Ay! Sudamérica" en Revista de crítica cultural. Arte y política desde 1960 en Chile. 29/30, 2004, p. 45.

Grau, Olga, "Memoria y representación: cuerpos y lenguajes heridos", en Utopía (s) 1973-2003. Revisar el pasado, criticar el presente, imaginar el futuro, ed. Nelly Richard, Santiago de Chile, ARCIS, 2004.

Maquieira, Diego, La Tirana, Santiago de Chile, Tempus Tacendi, 1983.

MartínEz, Juan Luis, La nueva novela, Santiago de Chile, Ediciones Archivo, 1985.

Neustadt, Robert, CADA día: la creación de un arte social, Santiago de Chile, Cuarto Propio, 2001.

O'HARA, Edgar, Isla Negra no es una isla: el canon poético chileno a comienzos de los ochenta; entrevistas, Valdivia, Barba de palo, 1996.

RICHARD, Nelly, "Roturas, memoria y discontinuidades (en homenaje a W. Benjamin)", en La insubordinación de los signos, Santiago de Chile, Cuarto Propio, 1994.

SARLO, Beatriz, "Historia y memoria. ¿Cómo hablar de los años setenta?", en Utopía (s) 1973-2003. Revisar el pasado, criticar el presente, imaginar el futuro, ed. Nelly Richard, Santiago de Chile, ARCIS, 2004.

VALDÉs, Adriana, "Una escena y varios fragmentos", en Utopía $(s)$ 1973-2003. Revisar el pasado, criticar el presente, imaginar el futuro, ed. Nelly Richard, Santiago de Chile, ARCIS, 2004.

ZuRITA, Raúl, "Presentación", en La cultura autoritaria en Chile de José Joaquín Brunner, Santiago de Chile, FLACSO, 1981.

— Purgatorio [1977], Santiago de Chile, Universitaria, 1996. 
